\title{
Discurso estético y discurso político en la crítica* del modernismo hispanoamericano
}

\author{
Marcos Olalla**
}

\begin{abstract}
Resumen
Analizamos en un sector del profuso corpus crítico del modernismo hispanoamericano algunas de sus tendencias. Destacamos en ellas su potencial para articular las dimensiones estética y política del fenómeno. Caracterizamos el modo como se ha tramado la relación entre tradiciones críticas diversas desde el nivel más elemental de la contraposición de aquellas dimensiones al nivel más complejo de su complementariedad, en un despliegue que permite establecer la pertinencia de un análisis que bascula entre el texto y su lugar de enunciación, al tiempo que habilita un diálogo entre los campos de la crítica literaria y los estudios culturales.

Palabras clave: modernismo, hispanoamericano, crítica, estética, política.
\end{abstract}

\section{Abstract \\ Aesthetic and Political Discourse in the Critique of Hispano-American Modernism}

This paper analyzes some of the trends in one sector of the extensive corpus of critique of Hispano-American Modernism. It highlights their potential to articulate the aesthetic and political dimensions of the phenomenon. It outlines the interweaving of the relationship between diverse critical traditions from the most elementary level of contrast to the most complex level of complementarity. This display allows for

\footnotetext{
* Recibido: junio 2017. Aceptado: julio 2017.

** Instituto de Ciencias Humanas, Sociales y Ambientales/Consejo Nacional de Investigaciones Científicas y Técnicas, Universidad Nacional de Cuyo. Mendoza, Argentina. Email: marcosolalla@gmail.com
} 
establishing the relevance of an analysis that swivels between the text and its locus of enunciation, enabling a conversation between the fields of literary critique and cultural studies.

Keywords: Modernism, Hispano-American, Critique, Aesthetics, Politics.

La historiografía de América Latina señala a 1880 como índice del período caracterizado por la definitiva consolidación de sus Estados nacionales. La organización estatal latinoamericana se realizó bajo el signo de la administración y dominio oligárquicos. Las ideas liberales en materia política orientaron este proceso y promovieron la modernización de sus respectivas naciones. La modernidad latinoamericana se produjo mediante el ingreso a la economía mundial por vía de la exportación de materias primas. De este modo se configuraba su condición "dependiente" (Osorio, 2000: 55), uno de los rasgos específicos del itinerario modernizador del subcontinente. El despliegue de este proceso impactaría dramáticamente sobre la fisonomía de las élites latinoamericanas. Los letrados, un sector significativo de estas últimas, se verían particularmente afectados por los cambios sociales operados por la modernización, puesto que se establecían las condiciones para un desencaje de las élites políticas burguesas respecto de los operadores -en un tiempo inmediatamente precedente- de la construcción narrativa de la nacionalidad. El letrado finisecular, habiendo concluido con éxito su tarea cívica, debía mudar su función social.

La expresión de la búsqueda de un nuevo lugar de enunciación específico para el vector letrado en el campo artístico fue la consumación de un movimiento literario al que sus propios cultores denominaron "modernismo". Su condición de expresión cultural del proceso de modernización; así como su contribución a la creación del momento de establecimiento de la autonomía del campo literario respecto del campo político; y su configuración como un documento de emancipación simbólica respecto de la tradición literaria hispánica; convierten a este fenómeno, en virtud de su alcance y riqueza, en cifra de la historia cultural latinoamericana.

Por ello, los modos de caracterización crítica del modernismo hispanoamericano constituyen documentos de un determinado estado del campo cultural en el momento de su enunciación, aún a sabiendas que se trata de un atributo de todo discurso. En efecto, la crítica del modernismo es singularmente rica en tomas de posición de fondo sobre los diversos modos de representación de la cultura de América Latina. 


\section{Miradas críticas}

El modernismo hispanoamericano constituye la manifestación literaria de los procesos operados al interior de la cultura hispánica aproximadamente entre los años 1880 y 1920. La condición radicalmente heterogénea de sus recursos estéticos y de sus matrices ideológicas dificulta la construcción de una imagen unívoca del movimiento y amplía el campo de sus interpretaciones según las coordenadas utilizadas en su caracterización. La profusa crítica que da cuenta del fenómeno modernista obliga a recortar su campo en función de ciertos ejes que permitan desarrollar una síntesis consistente.

La crítica del modernismo ya había transitado cinco décadas para cuando el estudio de N. Davison (1971) sobre la crítica hispánica organizó su análisis sobre un criterio que ofrecía una cierta orientación. De los elementos que Davison caracterizaba como objetos de "consenso" en la crítica del modernismo podían desprenderse dos grandes tradiciones críticas que nutrirían sus tematizaciones. Una tradición que definía al modernismo en función de los recursos estéticos empleados, caracterizada como "estetismo", y otra que pretendía reconstruir la sensibilidad histórica modernista, capaz de incluir el aporte tan profuso como contradictorio, de aquellos recursos, caracterizada como "epocal". En el mismo momento en que lo hacía Davison fue publicado un estudio que reseñaba la bibliografía crítica del modernismo por parte de E. Barbará de Bittar. Ella resaltaba allí la divergencia de tradiciones en términos de una consideración del modernismo como escuela literaria o como "movimiento general de la cultura" (1970: 12).

Podemos observar también las oscilaciones de la crítica en las caracterizaciones del modernismo hispanoamericano junto al modo de historiarlo. El concepto y la historiografía del modernismo fueron, en las primeras décadas de su estudio, los problemas fundamentales de una crítica cuyo entramado resultaría continuamente redefinido ${ }^{1}$.

La tendencia inicial de la crítica hacía partir al modernismo de la publicación del Azul de Rubén Darío, hacia 1888. Entre los rasgos específicos adscriptos al movimiento se señalaba cierto carácter cosmopolita, gran originalidad literaria, así como también la apropiación de todo lo moderno europeo, de entre lo cual destacaba la influencia de la literatura francesa (Cfr. Arellano, 1993: 28-29).

\footnotetext{
${ }^{1}$ Además de los trabajos de Davison y Barbará de Bittar tenemos en cuenta el artículo de Luis Monguió (1974: 10-22) para diagramar un posible itinerario de caracterización de un corpus extremadamente amplio, en cuyo análisis resulta imposible avanzar sin reflejar una cierta arbitrariedad.
} 
El mismo año de la publicación de Azul Juan Valera en sus Cartas americanas examinaba la escritura de Rubén Darío, cuya originalidad de estilo, su espíritu cosmopolita, su cultivado acervo literario, añadido a su elogiosa percepción de lo moderno europeo, se habría encontrado destinada a crear una escuela al cobijo de cierto afrancesamiento, condenada, por tanto, a expresar la inmoralidad y el pesimismo de la señalada impronta (1915: 272).

Manuel Machado en La guerra literaria se mantenía en un tipo de caracterización textualista del modernismo, aunque introduciendo un matiz distinto a aquel que reduce el sentido interno de lo literario al estilo. La referencia era la obra modernista como objeto de una posición del escritor al interior del campo literario de orientación anárquica. El modernismo venía a ser la liberación por parte de esta generación de escritores de los anteriores dogmatismos (1913:32).

Manuel Gálvez señalaba como rasgo distintivo de la producción modernista, la reconversión del lenguaje literario en función de una virtual descomposición del componente retórico de la poesía. Ese lenguaje expresaba una musicalidad que exigía un modo distinto de fluidez. Asimismo, determinaba fuertemente su creciente relevancia por cuanto la poesía se transformaba de ejercicio retórico a vehículo de cultura (1961: 19).

A una cierta distancia de las posiciones destacadas precedentemente se encuentra la lectura que del modernismo realizara el cubano Juan Marinello en su José Martí, escritor americano: Martí y el modernismo (1958) y Sobre el modernismo: Polémica y definición (1959). La ubicación de su lectura resulta paradójica en el escenario de la crítica del modernismo. Desplegaba un análisis de las condiciones de producción de la obra modernista, pero le asignaba una relevancia exclusivamente estética. Dicha asignación suponía la postulación de una cierta defección ideológica. Así, una forma de lectura del modernismo apegada a la teorización del vínculo entre la obra y su contexto social de producción aparecía como paradigma de la lectura "estetista" (Davison, 1971: 75 ss.) del movimiento. Las claves formales de la renovación modernista pasaban, según el cubano, por una pretensión de superación de lo previo en términos de novedad formal, como elaborada experimentación, en el marco de un rechazo por las tradiciones hispánicas y la afirmación de valores estéticos de cuño francés. El presunto apoliticismo modernista se convertiría en un tópico característico del discurso crítico antimodernista (Cfr. Maíz, 2007: 97ss.). Aquel tópico daba cuenta de que el foco estaba puesto en las innovaciones estrictamente formales de la literatura y por lo mismo se interpretaba a dicha producción como una forma de desenganche de su coyuntura política. 
El carácter estético del discurso modernista no inhibía, sin embargo, un particular modo de codificación de la cultura ni las formas en las que ésta impacta sobre las aspiraciones de los distintos sujetos sociales. Ya en 1899, en el ensayo Rubén Dario el crítico y escritor uruguayo José E. Rodó pretendía dar cuenta de cierta trabazón entre los rasgos literarios y los culturales en el modernismo. Resultado de este cruce era la percepción por la cual el lenguaje modernista estaba profundamente vinculado a excéntricos refinamientos, a un cosmopolitismo exquisito y a un fuerte personalismo de sus cultores, no exento de anarquismos idealistas ni de cierta amoralidad (1956: 155).

En esta línea se desarrollarían las lecturas de Manuel Ugarte (1908) y de Rufino Blanco Fombona (1929). La crítica de Ugarte evaluaba la potencialidad política del discurso estético modernista en función de sus posibilidades de representación de la nacionalidad continental. Para el venezolano, en tanto, el modernismo incluía rasgos específicamente americanos. Dicho movimiento evolucionaría hacia una resolución latinoamericana de su original afrancesamiento. De modo que, al par de las innovaciones formales, el modernismo era considerado como expresión de la identidad latinoamericana en el horizonte de un discurso político de integración. Esta modalidad de la crítica modernista tendía a enfatizar la relevancia de la presencia en esta corriente de temas latinoamericanos.

En el marco de esos desplazamientos de la crítica, se sostenía que el modernismo hispanoamericano era la expresión estética americana de la crisis cultural de fin de siglo, suscitada por las proyecciones del proceso de modernización capitalista en la región. Federico de Onís en el artículo titulado "Sobre el concepto del modernismo" [1953] (1974: 35 ss.) sintetizaba una posición que perfilaba desde la década del 30 en diversos textos y que se encontraba destinada a convertirse en una inflexión para la crítica del modernismo. Onís caracterizaba al modernismo como una profunda revolución en toda la cultura hispánica en la que esta última imprime rasgos originales a un "movimiento universal". Así, es posible para el crítico español comparar al modernismo hispanoamericano con el Renacimiento español, tesis que, por otra parte, había sostenido Alberto Zum Felde (1921: 203). El grado de inclusividad así previsto en esta interpretación del modernismo obligaba a tematizar las relaciones de éste con la generación española del 98; dirección muy fructífera para la crítica en los años que siguieron a la formulación de la tesis epocal, tanto para afirmar sus vínculos en la línea antes citada -tal es el caso de la obra de Ricardo Gullón Direcciones del modernismo (1963)como para determinar sus diferencias. En esta concepción se encuentra el clásico texto de Guillermo Díaz Plaja, Modernismo frente a Noventa y ocho 
(1951), deudor de las intuiciones que previamente desarrollara Pedro Salinas [1939] (1949: 13-25). No obstante, esta última dirección tiende a reduplicar la divergencia entre estetismo y epocalismo para atribuirle el primer carácter al modernismo y el segundo a la generación del 98, en un movimiento que anulaba las tensiones al interior del propio modernismo, provocando una nueva simplificación, oportunamente cuestionada por Rafael Ferreres [1955] $(1964)^{2}$.

Hay evidencias que dan cuenta del carácter precursor de una lectura semejante por parte de Juan Ramón Jiménez, también a partir de los años 30, y cuya exposición sistemática se daba en El modernismo; notas de un curso (1953) (1962). Para el escritor español el modernismo estaba lejos de ser un conjunto de recursos formales por lo mismo que las influencias en este marco perdían la relevancia otrora adquirida. Los usos de tales elementos por parte de los modernistas se comprendían en sentido aleatorio como orgánicos a una determinada "actitud" frente a la belleza y esta última, sedimentada en la poesía de talante burgués del siglo XIX. El "entusiasmo" y la "libertad" de experimentación estética es lo que caracterizaría al modernismo en el marco de esa orientación de la crítica.

La lectura de Alberto Zum Felde en Proceso intelectual del Uruguay y crítica de su literatura tendía a morigerar la representación libertaria del modernismo por cuanto le despojaba de su arraigo social. Caracterizaba a dicho movimiento como una síntesis de recursos provenientes del parnasianismo, el decadentismo y el simbolismo; escuelas que poseían en común la búsqueda de nuevas experiencias literarias que se desplegaban en un registro psicológico, en desmedro de su cauce estético o político. El modernismo aparecía como la expresión de una transición conductual consecuente con el rechazo a las formas del pasado (1930: 17).

La transición así caracterizada por el crítico uruguayo había sido propuesta unos pocos años antes por Erwin Mapes en su análisis de las influencias francesas en la obra de Rubén Darío, asumiendo la posibilidad de dicho proceso en virtud de un cierto afrancesamiento de las letras castellanas, no en orden a señalar meras influencias, sino en función de determinar el modo como la apropiación modernista de la estética de cuño francés daba cuenta originalmente de aquella transición (1925: 108).

\footnotetext{
${ }^{2}$ Ferreres señalaba que existía una evidente comunidad de "temas, técnica estilística, preocupaciones literarias, artísticas, políticas y religiosas" entre los autores modernistas y los de 98 (1964: 83-84). La dificultad de la crítica española para establecer qué autores ibéricos se encontrarían en un dominio u otro del campo literario, constituiría una evidencia de que el modernismo fue una expresión de la renovación que atravesó la totalidad de dicho campo a fines del siglo XIX y principios del XX.
} 
A principios de los años cuarenta Pedro Henríquez Ureña [1949]³ (1980: 212) afirmaba que la disciplina técnica apropiada por los modernistas desde las influencias europeas constituía una liberación americanista del tradicionalismo romántico. Poco más de una década después Max Henríquez Ureña [1954] (1962: 30), por su parte, definía el talante modernista en términos de una renovación formal, por un lado, y de una renovación espiritual, por otro. Así, además de las influencias parnasianas y simbolistas en el orden formal, debía reconocerse la impronta humanista de los modernistas expresada en su fuerte cosmopolitismo, una forma de idealismo destinado a convertirse en percepción trágica de la vida.

El crítico cubano Iván Schulman $(1969,1987)$ reconocía en la tradición que iba de F. de Onís a M. Henríquez Ureña la virtud de revalorar la obra modernista en función de su significación estética, filosófica y social, por cuanto dicho movimiento abría una multiplicidad de experiencias ligadas a una vocación libertaria que se expresaba en la revisión de los parámetros estilísticos, lingüísticos y doctrinarios precedentes. En este orden de cosas, el discurso que cristalizaba de modo cabal en la obra de Darío resultaba posibilitado por la promoción de un cambio estético e ideológico iniciado por José Martí y Manuel Gutiérrez Nájera y reflejaba su espíritu renovador, su preocupación filosófica e ideológica y su pluralidad estética.

En la década del sesenta la lectura política de la literatura argentina realizada por David Viñas contribuyó de modo decisivo a la caracterización del modernismo en términos de su problemática relación con el orden estatal. Viñas [1964] (1996), problematizó el contexto de producción del modernismo hispanoamericano en términos de "crisis de la ciudad liberal". La literatura de la generación del ochenta argentina, fue cultivada por "gentlemen" (9), que se ocuparon de ella como una cuestión periférica. Este dato constituyó el antecedente desde el que los modernistas habrían reconocido el complejo estado de la relación entre literatura y poder. La especificidad modernista en la resolución de esta relación se hallaba atada a una serie de conflictos socio-políticos y culturales irreductibles a los esquemas tradicionales de la producción literaria. Este orden de cosas habría dado lugar al surgimiento de movimientos literarios de raíz latinoamericana que expresaban las fracturas del sistema de la cultura, como consecuencia del afianzamiento del proceso modernizador y que, por lo mismo, tendían a representar su presente sobre el fondo de dos universos antagónicos: la tradición cultural y la modernización burguesa. La creciente diferenciación

\footnotetext{
${ }^{3}$ La primera edición de este texto se realizó en inglés en 1945 por la Universidad de Harvard y es resultado de sus cursos sobre la materia en Cambridge entre los años 1940 y 1941.
} 
modernista de ambos extremos de aquella dicotomía explicaba la presencia en su discurso de contradicciones, ambivalencias, equívocos y ambigüedades (40), que habilitaban la razonable reserva respecto de la viabilidad de la atribución de una única matriz ideológica para esta formación cultural. Esta reserva sería enfáticamente destacada, poco más de diez años más tarde, por el influyente artículo de Carlos Real de Azúa sobre la ideología del modernismo [1977] (1986). Las tensiones inherentes a la autorrepresentación modernista de su rol histórico exigía una caracterización, que al par de señalar sus contornos, diera cuenta de sus soportes discursivos. El crítico argentino avanzó en la determinación de las filiaciones políticas del modernismo con intuiciones que luego serían desarrolladas con mayor sistematicidad por la crítica latinoamericana en las décadas siguientes ${ }^{4}$.

Al tiempo que Real de Azúa publicaba su célebre artículo, Saul Yurkievich contribuía al campo de la crítica del modernismo con un texto de significativa relevancia $(1976)^{5}$, en el que afirmaba que las condiciones objetivas de producción de la obra modernista daba cuenta, no tanto de la circunstancia que rodeaba a la misma, como de una percepción particular del mundo que, aun con su consecuente epocalidad, se revelaba como "efectividad estética". Entre los elementos que a juicio del escritor argentino expresaban esta percepción se encontraba la voluntad de ruptura, y con ello, la conciencia de que se estaba operando una transformación de la literatura en lengua española. Dicha ruptura movilizaba una sensibilidad transgeográfica propia del "arte de 1900". En este contexto resultaba fundamental el grado de inflexión que para la producción modernista poseía la promoción del cosmopolitismo, en lo que constituía, un discurso de matriz metropolitana. Todos los recursos necesarios para describir la inherente mutabilidad del mundo moderno eran utilizados por los modernistas, promoviendo de este modo cierta complejización del signo poético. Por otra parte, la profesionalización de la literatura latinoamericana constituía un efecto ineludible del desarrollo de la sensibilidad así desplegada. La actitud consciente y programática, en términos de las experiencias de autonomía y ruptura del modernismo respecto de tradiciones previas, acercaban al movimiento al lenguaje del "manifiesto", tan caro a la vanguardia posterior.

\footnotetext{
${ }^{4}$ No obstante, la ausencia de la referencia a la obra de Viñas en la crítica literaria latinoamericana posterior se explica por carecer de una proyección continental, como bien lo ha destacado Gonzalo Aguilar (2010: 157).

${ }^{5}$ Los estudios de Yurkievich sobre el modernismo incluyen su trabajo titulado La movediza modernidad (1996).
} 
Otra de las expresiones de la crítica del modernismo que se halla en la línea de interpretación aquí reseñada es la obra de Rafael Gutiérrez Girardot (1983, 1987). Para el crítico colombiano el modernismo hispánico respondía a los efectos de dos procesos: la integración de Hispanoamérica y la disolución de la sociedad tradicional en el marco de la formación de la sociedad burguesa. Como consecuencia del cruce de estos procesos en el ámbito de la literatura hispanoamericana se produjo una renovación en la autocomprensión del artista al interior de la estructura social, la promoción de una interpretación secularizadora de la vida, así como una lectura de la misma mediada por la experiencia urbana.

Para el crítico argentino Noé Jitrik el modernismo debía comprenderse como un momento de la historia de la escritura en América Latina en la que éste opera como una impugnación radical de la cultura poética de su tiempo en dirección de una superación de la concepción contenidista de aquella. Tal experiencia de la inflexión operada en la modificación de la materia poética daba cuenta de las rupturas con aquella tradición. En esta constelación estético-política encontraba sentido un rasgo fundamental del sistema modernista, como es la promoción de la "originalidad". Este rasgo constituía el eje sobre el que se concebían diversos procedimientos de "subjetivación" en torno del cual los atributos del sujeto, lejos de incorporarse a un registro unívoco que funcionaba como núcleo integrador, tendía a favorecer su dispersión. Este movimiento constituía un recurso que, al par de poner de manifiesto el proceso de "profesionalización" del escritor en su proceso de delineamiento de su rol en la estructura social, expresaba la pretensión política inherente a la forma del discurso modernista (Jitrik, 1987: 51 ss.).

El sistema modernista resultaba una expresión ideológica que remitía a la conformación de una figura nueva del intelectual respecto de los rasgos que el siglo XIX le asignaba. Si bien la ratio fundamental de la que da cuenta dicho sistema se hallaba en la configuración globalizante del capitalismo en la que América Latina se insertaba, su condición dependiente instalaba un registro propio en el vínculo relativamente idéntico que se daba en el régimen económico de los países centrales entre subjetivismo y capitalismo. Así, el esquema agrario de la producción latinoamericana funcionaba como fondo para una inscripción revolucionaria de la "fabricación" subjetivadora modernista. Ésta última, en tanto, se ofrecía como modelo, desde la escritura, para la modificación de las condiciones materiales de producción. Jitrik se separaba de una representación determinista del modernismo puesto que revelaba la productividad de la experiencia modernista de "subjetivación" como horizonte de 
una forma de acción que, si bien operaba sobre la escritura, deconstruía un orden de cosas cuya sedimentación tendía a inhibir el carácter dinámico de la historia. Afirmaba el crítico:

Y, en la acción, acaso los modernistas recuperan la "subjetividad", pero ya no como argumento histórico filosófico sino como espacio de un "sujeto" que se constituye en su movimiento de producción, como haciendo oposición, desde la subjetividad constituida, al marco en el que yace socialmente la palabra, sometiendo a un pasado que perdura en ella y que viene de las formas de explotación económica; esa palabra sujetada, no subjetivizada, cuyo imperio el modernismo viene a quebrantar, frena el "deber ser" que desde una conciencia histórica puede ser previsto, alentado y esperado (1978: 9).

El rechazo de los valores burgueses desde una concepción aristocratizante, no desprovista de gestos anarquistas, la aplicación de diversos modelos estéticos europeos como esfuerzo de adelanto cultural e invocación epocal y el desarrollo de un lenguaje nutrido de una gran riqueza acentual y rítmica, eran tópicos comprendidos al interior de un discurso caracterizado por su condición de operador de un proceso de subjetivación intuido como fuente de una praxis crítica, cuyas proyecciones políticas resultaban regularmente examinadas.

Para Jitrik, la presencia del "subjetivismo" daba cuenta de la condición poética de la incorporación de una matriz política liberal que operaba como ideología del "industrialismo fabril" (120) y que intentaba ser articulada con una vocación autonómica ligada al reacomodamiento de la figura del intelectual. Si esta matriz se revelaba eficaz como recusadora de los componentes arcaicos de la tradición cultural, resultaba incapaz de integrar en su representación de la hora histórica elementos contradictorios, como son, por un lado, el carácter emancipatorio de la promoción de "originalidad" en el campo de las producciones culturales y, por otro, la condición dependiente de la incorporación de América Latina al régimen económico que daba sentido a las proyecciones políticas del discurso modernista. En tal caso, la experiencia de esta contradicción promovía la configuración de un elemento simbólico compensatorio que poseía como dato de origen la imposibilidad de un desarrollo satisfactorio de las fuerzas políticas que habilitaban una reforma estructural de esta índole ${ }^{6}$.

\footnotetext{
6 “[E]n nuestros países, en donde nace y algo significa el modernismo, lo más entrañable de los conceptos que permiten la reestructuración del capitalismo europeo y que desembocan en una ideología del industrialismo fabril, no encuentra condiciones para una aplicación inmediata; como tampoco hay posibilidades de una elaboración sólo queda el camino de la aceptación indiscriminada. El grado de modificación es escaso,
} 
El modernismo se presentaba como una "revolución poética" que integraba diversas matrices estéticas en su esfuerzo de acceder a la universalidad negada por la tradición literaria latinoamericana. Sobre el fondo de dicha pretensión se comprendía la afinidad de su código artístico con el desarrollo del liberalismo político, aunque éste no constituyera un límite preciso del espacio ideológico en el que se movía 7 .

La obra del crítico uruguayo Angel Rama (1983) supuso una verdadera inflexión crítica por cuanto sistematizó el análisis del cruce entre el campo literario y el campo del poder. Su lectura del fenómeno modernista ofreció una visión que por consistente no era menos matizada. En ella el crítico comenzaba por dar cuenta del carácter autonomizador de la obra modernista inaugurando con ello lo que Rama caracterizó como "conciencia reflexiva del arte" (78). Los modernistas eran conscientes que la autonomía del campo literario sólo podía consumarse a fuerza de una verdadera decodificación de aquellas ideas que el arte movilizaba, objeto de la perpleja percepción cotidiana y fruto, por tanto, de la experimentación en dicho campo. Este paso fundamental constituyó la definitiva superación del apego romántico al registro meramente expresivo de la literatura.

Los planteos modernistas políticamente más orgánicos respecto de las demandas de su tiempo se posicionaron en el horizonte americanista, en el marco de un cosmopolitismo cuyo guiño al programa unificador mundial capitalista resultaba evidente. Sin embargo, esa percepción no fue obstáculo para una crítica del rol de América Latina en tal escenario. Las representaciones de Latinoamérica fueron diseccionadas por los modernistas en un innegable gesto cosmopolita, que no supuso sin más una forma de despolitización de la problemática, sino que constituyó una cierta "búsqueda dentro de la alienación” (89) que aquel programa efectivamente suscitara. La pluma modernista avanzó en clave crítico-desacralizadora de los valores burgueses todavía emergentes. La irreverencia no era mera impostura en este sentido, sino un

salvo en el plano de la ideología en el que se advierte un pasaje bastante espectacular de un tipo de vida criolla y patriarcal, relativamente religiosa, a un estilo aristocratizante y superficialmente descreído, en el que la ciencia y la cultura juegan el papel de necesario barniz" (Jitrik, 1978: 120).

${ }^{7}$ Sohyun Lee estima que la contradicción en la que se funda la mirada modernista sobre el presente atiende más a la percepción del fracaso de la ideología liberal para producir el progreso material postulado para América Latina que a la invocación desde la escritura de una fase industrialista del capitalismo todavía ausente. "En vista de que la diferencia que divide a las dos sociedades -la materialista anglosajona y la idealista latinoamericana- se hacía cada vez más grande, resurge con mayor fuerza la contradicción con la que había partido el pensamiento modernista: desear y devaluar al mismo tiempo el desarrollo material que nunca se dará en América Latina” (2004: 97). 
discurso crítico sostenido por un registro moral cuyo principio articulador fue la postulación de la unidad que haría posible la superación de las contradicciones y la fragmentación de la sociedad latinoamericana.

En este contexto la tematización en clave hedonista que el modernismo realizó de la subjetividad adquirió un nuevo significado. Lejos de constituir una aristocrática evasiva, se manifiestó como crítica a la creciente "inhumanidad" de aquel proceso en el que el modernismo, aunque críticamente, estaba inserto. Así también, avanzó, no exento de contradicciones, en dirección de una democratización estética. En efecto, la revolución operada por el lenguaje poético del modernismo constituyó el espacio para una nueva integración, la del "decir americano" (99).

La democratización funcionaba como el significante que daba cuenta del carácter universal de las demandas de un sujeto social emergente. La tonalidad burguesa de aquella se nutrió de expresiones culturales que fungieron como dispositivos políticos. En este orden de cosas, el proceso democratizador operado en América Latina a partir de 1870 como fruto de la expansión económico-imperial puso de manifiesto, por un lado, la segmentación de los extremos en disputa y, por otro, el grado de violencia vinculado a su irrupción (Rama, 1995a: 120). Los intelectuales ligados a la tradición aristocrática de la cultura latinoamericana percibieron aquel proceso como amenaza ${ }^{8}$. Si frente a ella la intelectualidad patricia se apoyaba en un discurso nacionalista, era evidente, para otros agentes del campo cultural, que aquella coyuntura exigía otros modos de representación. Ésto explicaba la recurrencia de la evocación del carácter transicional presente en la imagen epocal de los modernistas.

La historicidad operante en la autorrepresentación de los autores ligados al modernismo instalaba el relato sobre el pasado en el registro de la transformación simbólica y material de la que se concibían como agentes y develadores. De este modo, desarrollaron una incorporación ecléctica de recursos que nutrieron el relato, en virtud de cuya interpretación el presente se asumía como horizonte de democratización. Rama mostró, sin embargo, que tales recursos estaban inscriptos en una matriz tradicionalista que inhibía los elementos morales y políticos más revulsivos en beneficio de una actitud contemplativa (127). Para el crítico uruguayo el discurso modernista puso en

\footnotetext{
8 "La modernización burguesa y dependiente acarreaba una democratización que desquiciaba los valores establecidos y chocaba con los hábitos elitistas de la vida intelectual latinoamericana" (Rama, A., 1995a: 121). Esta línea de interpretación ha sido desplegada en el estudio crítico de Graciela Montaldo sobre este período de la producción literaria latinoamericana titulado La sesnsibilidad amenazada. Fin de siglo y modernismo (1994).
} 
juego una lógica que "enmascaraba" los dispositivos culturales inherentes a las formas de dominación tradicional e imperial bajo un ropaje democratizador (Rama, 1985c).

Con todo, resultaba innegable la ampliación del lenguaje poético realizada por los modernistas en dirección de una creciente anexión del lenguaje natural, aunque incorporado en una "aristocrática selección lexical" (Rama, A., 1995b: 86). En tal sentido, la democratización, concebida en términos descriptivos como documento de ascenso social, daba cuenta de la emergencia de los sectores medios, todavía incapaces de "modificar el encuadre fijado drásticamente por el ejército y la oligarquía comerciante" (89). Rama comprendió las manifestaciones culturales de esta forma específica de emergencia como "modernización literaria" (90) y la circunscribió al período que va de 1870 a 1910.

La modernización ofreció las condiciones para la configuración de un movimiento intelectual creador del "sistema literario latinoamericano" (87) que, al tiempo que fundaba en su conciencia de la autonomía del campo literario su discurso estético, provocó un deslizamiento del rol del intelectual latinoamericano de la participación política directa a la constitución de la figura de conductor espiritual de la nación (71). Se profundizó así la sacralización de la función cognitiva desplegada en torno de la explicación del sentido del proceso histórico por parte de este selecto grupo de cultores de la inteligencia (92).

Los estudios que Rama dedicó al modernismo contribuyeron a la comprensión de la tensión entre los registros estético y político que atravesaron la producción literaria del período. En la tradición iniciada por F. Onís, continuada, pero también muy enriquecida, por I. Schulman $(1969,1987)$, I. Zavala (1992), C. Real de Azúa (1986), L. Litvak (1980), G. Montaldo (1994), G. Kirpatrick (2005), R. Gutiérrez Girardot (1983, 1987), N. Jitrik (1968, 1978, 1987), A. Rama (1983, 1985a, 1985b, 1985c, 1995a, 1995b), J. Franco (1971), J. Ramos (1989), A. J. Pérez (1995), Miguel Gomes (2002) y muchos otros, se configuró un registro de análisis que era capaz de reconocer aquellas tensiones en términos de un esfuerzo de articulación de los datos ideológicos y los tópicos estéticos.

\footnotetext{
9 “También aquí la democracia era un disfraz que no dejaba de ser real y disfrutable, por más que hubiera encontrado la convergencia oculta entre la tradición autoritaria que tenía siglos en el continente y el nuevo orden económico que propiciaban los imperios de la hora. De tal manera que la América Latina que se incorporaba ancilarmente a la economía-mundo occidental sumaba al guardarropas universal que proponía la sociedad europea una sección propia de máscaras” (Rama, A., 1995a: 128).
} 


\section{Modernismo hispanoamericano y subalternidad}

Un campo que ha dialogado de modo fructífero con los estudios literarios y la historia de las ideas es el de los estudios culturales. En efecto, el inicio del despliegue de este campo se comprendió como una ampliación del concepto de cultura en la escena de las señaladas disciplinas. Nos interesa destacar la inflexión de la crítica cultural latinoamericana en la problematización del fenómeno modernista como un aporte a la trayectoria seguida por aquellos estudios que hicieron foco en la dimensión política del discurso modernista en términos de su identificación de las estrategias hacia dentro y hacia fuera del campo literario de las intervenciones modernistas.

Como hemos indicado previamente, la profusa gama de experimentos formales en la producción literaria modernista hacía difícil la determinación de una síntesis del movimiento en términos estéticos y por otro lado, una versión más preocupada por las condiciones históricas de su formación se encontraba frente a la imposibilidad efectiva de realizar una síntesis ideológica en virtud de la diversidad de opciones políticas desplegadas por los modernistas (Real de Azúa, 1986). En tal contexto se tendía a converger en una definición matizada de esta última versión de la crítica del modernismo, que le atribuía como núcleo de esta impronta literaria una actitud comprometida con la crisis cultural de fines del siglo XIX y que se habría extendido hasta las primeras décadas del siglo XX, explicando de este modo la búsqueda formal modernista al par de su manifiesta heterogeneidad. Esta trayectoria fue caracterizada por la crítica de la cultura latinoamericana Iris M. Zabala. La conclusión de la teórica, en la línea de una radicalización de la dirección abierta por Onís, aseguraba, para el modernismo, la posesión de un carácter antiautoritario, socialista y anticolonial (1992: $129 \mathrm{ss})$.

En el espectro crítico del proyecto poscolonial la cuestión del modernismo hispanoamericano estaba particularmente presente en la crítica del latinoamericanismo de Santiago Castro Gómez que se conoció en la influyente obra Crítica de la razón latinoamericana (1996). El filósofo colombiano cuestionaba la imagen emancipatoria del modernismo identificando en su discurso una cierta reafirmación del legado abierto por la kantiana categoría de "estética de lo bello" (137).

Para Zavala el perfil subjetivo de quienes encarnaban el modernismo constituiría una experiencia de los márgenes de la sociedad latinoamericana al interior del proceso modernizador burgués de fines del siglo XIX y principios del XX. Así, confluían en esta corriente proyectos de matriz bohemia, 
anarquista y feminista, produciendo narrativas de talante emancipatorio, cuyo objeto era la construcción de una sociedad desalienada, emancipada de las coerciones de la razón instrumental (1992: 108 ss).

Este rasgo, para Castro Gómez, constituía la confirmación de que los textos modernistas se integraban en la promoción de un tipo de sociedad cercana a la que postula la estética de lo bello. En efecto, la tendencia a la unidad y la armonía en la estética de lo bello y en el modernismo le imprimiría el sello de burguesa a aquella crítica contra el sentido instrumental de la modernización y su carácter homogeneizador. Todavía más, la autopercepción modernista de su condición fundacional en la autonomización del campo literario, sería una señal de organicidad con la modernidad en sentido weberiano.

Si bien Castro Gómez atribuía razón a Zavala respecto del potencial crítico del modernismo hacia las direcciones del proceso modernizador latinoamericano ${ }^{10}$, el modernismo se habría desarrollado sobre la base de una dinámica moderna consistente en la promoción de diversas formas de invocación de "unidad" que contribuirían al desarrollo de dispositivos disciplinarios.

El crítico colombiano se apoyaba en la crítica de A. Rama para realizar su proyecto de deconstrucción de la historia de las ideas latinoamericanas representada en los trabajos de Leopoldo Zea y Arturo Roig, quienes habrían desarrollado una narrativa de la autoconciencia continental con materiales procedentes, exclusivamente, de las formas de representación letrada, agencia privilegiada de cognición de la cultura latinoamericana. En este orden el saber se imponía como el espacio donde la relación significante-significado se resolvía, promoviendo un cierto "primado de la representación" (Castro Gómez, 1997, 124).

\footnotetext{
${ }^{10}$ Un estudio que va en la dirección emprendida por Zavala y que contribuyó a la consolidación de una imagen en buena medida contestataria del modernismo hispanoamericano, por la vía de fijar sus rasgos críticos en la categoría de "modernidad estética", fue realizado por el crítico rumano Matei Callinescu hacia fines de la década del ochenta [1987] (1991). La literatura latinoamericana de la modernidad intentó explicitar su problemática relación con el poder estatal mediante una gesticulación del giro hacia la autonomización del campo literario. Dicha autonomización obedeció a los patrones clásicos de la racionalidad moderna, al tiempo que fungió como una forma de diferenciación respecto del discurso que regulaba las prácticas político-institucionales de aquélla. El proyecto "modernizador" apareció como antagonista de la modernización literaria. Calinescu caracterizó este fenómeno como "dos modernidades": una modernidad que alude a la cultura generada en torno al desarrollo de los progresos científicos-tecnológicos, la revolución industrial y el capitalismo, denominada "modernidad burguesa"; la otra "modernidad como un concepto estético", cuya impronta antiburguesa se plasmó como "pasión negativa". Esta ruptura funcionó como germen para una categorización al interior de la literatura misma. Una literatura "filistea", orgánica a la reproducción de los intereses burgueses y una literatura "revolucionaria" que no se definía por su contenido ideológico sin más, sino en función de una "afirmación agresiva de la total gratuidad del arte" que operaría como provocación al gusto burgués (1991: 50-55).
} 
El grado de reflexividad aquí supuesto como rasgo ineludible de la producción cultural latinoamericana moderna le había permitido a Rama ocuparse de las prácticas literarias vinculadas a los saberes humanísticos y al modo como éstos operaban hegemónicamente (1985a: 27). La condición normativa de la escritura, estrechamente relacionada con la construcción de las nacionalidades latinoamericanas, habría determinado fuertemente el carácter disciplinario de la sociedad liberal.

Los márgenes del relato normalizador, cuyo objeto era la incorporación de América Latina a la dinámica del capitalismo internacional, quedaban integrados en el mismo. Castro Gómez destacaba el carácter reflexivo de la escritura modernista como una dimensión estructural, entre cuyos efectos se encontraría la configuración de una "gramática social" moderna en la que se pretendía representar a la sociedad como una totalidad, frente a la cual el sujeto de dicha representación se representaba a sí mismo.

La subjetividad del letrado no preexiste a la consolidación de la escritura como espacio de representación, sino todo lo contrario es "producida" desde la representación misma (Castro Gómez, S., 1997: 126).

Así, el siglo XIX vio nacer el objeto de conocimiento "sociedad" y, vinculado a ello, se promovieron saberes cuya mirada clínica tuvo una ostensible presencia en el campo cultural del período. Dichos saberes hallaron sentido en el hecho de "auscultar panópticamente [el] alma -del enfermo-" (127). El letrado se constituiría en profeta de los iletrados y su anuncio: la impronta reflexiva de la escritura. Ella habría promovido tanto saberes como formas de subjetividad vinculadas a la reflexividad.

Castro Gómez introdujo respecto del crítico literario uruguayo un matiz consistente en una ampliación de la noción de reflexividad hacia ámbitos no sólo cognitivos. La noción de reflexividad cognitiva aparecía demasiado ligada al "paradigma cognitivo-instrumental", no permitiendo detectar narrativas contrahegemónicas en el marco de la ciudad letrada. Así como esta última forma de reflexividad venía determinada por las demandas del sistema, en cuyo seno los roles son formulados por expertos, la reflexividad que Castro Gómez llamaba "hermenéutica" daba cuenta de la posibilidad, para ciertos discursos, de reconocer su exclusión del sistema representacional (130).

Estos grupos, aun cuando no pertenecieran a las élites, se vinculaban a la ciudad letrada en virtud de la creciente urbanización modernizante. Por ello se debía reparar en un efecto crítico de la modernidad en América Latina. Por otro lado, la experiencia de la exclusión no fue sólo vivida por tales grupos, 
sino por agentes inconformes de la ciudad letrada. El carácter de "otro" de estos últimos, en función de sus diferencias sexuales, políticas y sociales, determinaba fuertemente el sentido reflexivo de tal experiencia de la alteridad, promoviendo con ello "políticas contrahegemónicas de representación". E1 filósofo colombiano llamó "reflexividad estética" a dicha experiencia (131).

La incorporación de esta especificidad en la crítica de Castro respecto de la matriz ramiana no inhibió la impugnación de la aspiración modernista de "armonía". Este juicio se nutrió de la diferencia entre lo bello y lo sublime en la filosofía de E. Kant. En efecto, para Kant, lo bello de la naturaleza estaba señalado por la forma del objeto, es decir, por el carácter limitado del mismo, consecuente con su condición de concepto indeterminado del entendimiento. Mientras que lo sublime revestía el carácter de lo ilimitado de modo que había de hallarse en dicha representación un objeto desprovisto de forma en razón de lo cual constituía, a diferencia de lo bello, un concepto indeterminado de la razón. El modo de placer así determinado poseía como sentimiento, en el caso de lo bello, la vitalidad vinculada a los aspectos lúdicos de la imaginación. Lo sublime configuraba una experiencia de lo ilimitado en el objeto, al mismo tiempo como placer y como rechazo, en virtud de lo cual era caracterizado por Kant como placer negativo. Lo bello natural consistía en la conformidad entre su representación artística y el objeto natural. La naturaleza estructural de la señalada concordancia permitía al filósofo de Köenisberg hablar en sentido metafórico de una cierta predestinación para nuestra facultad de juzgar. Lo sublime, pensado en términos naturales, se revelaba como falta de aquella facultad, como violencia respecto de la imaginación, en su pertinaz intento de representación. Lo que se presentaba, aunque en el modo incierto de la incitación, era la misma sublimidad y con ella la forma de la capacidad de juzgar, cuya inconformidad revelaba su ánimo (Kant, 1992:160).

La especificidad de la experiencia modernista se habría resuelto, para el colombiano, en el marco de la lógica de la "conformidad". En efecto, el rechazo modernista a los valores de la burguesía se habría dado al interior de un discurso que poseía como horizonte la idea de una cierta "armonía preestablecida". Así, el rechazo a la política imperialista norteamericana sobre América Latina, una de cuyas expresiones fue la reacción a la intervención estadounidense en Cuba en 1898, vendría de la mano de la glorificación de la "cultura latina". En consonancia con esta percepción, se habría asumido un sesgo aristocrático como ideal de vida del artista. Las intuiciones estéticas de éstos les convertirían en privilegiados agentes de la huida de los intereses técnico-económicos. Para Castro Gómez, el proyecto modernista de representación de la cultura latinoamericana, fundado en la afirmación de 
la posibilidad de cognición de esta síntesis cultural, se vería refrendado por imágenes homogeneizadoras de la historia. Así debía comprenderse la idea rodoniana de retorno a una cierta "edad de oro" en su Ariel. En este discurso la armonía preestablecida habría funcionado como criterio de determinación para la construcción de una imagen unívoca de lo latinoamericano que se correspondería con el lugar de enunciación aristocrático del modernismo. La lógica de la conformidad que atravesaría esta noción de armonía convertiría a la producción modernista en una forma de despliegue de una matriz ideológica conservadora. Según Castro Gómez, esta inconsecuencia del modernismo en cuanto discurso alternativo al programa modernizador hegemónico, en virtud de su vinculación a la promoción de principios armonizadores del ser y deber ser latinoamericanos, prepararía el camino a la formación de regímenes autoritarios.

El proyecto crítico de Castro Gómez nos permite vislumbrar un aporte metodológicamente relevante para el análisis de las producciones culturales latinoamericanas en su dilucidación de los cruces entre discurso estético y discurso político. Sin embargo, ofrece una sobreinterpretación del fenómeno que extrapola la perspectiva del crítico a su objeto. Atribuye a la creación la perspectiva del lector y la juzga así deficitaria. Comprender al modernismo exclusivamente como discurso normalizador y como mecanismo disciplinario supone desconocer las tensiones y heterogeneidades propias de las múltiples expresiones de un corpus extenso. La historización de los antagonismos que tensionan el discurso modernista constituye la condición de una crítica de la cultura capaz de descubrir en sus textos los diversos registros que expresan las múltiples formas de la conflictividad.

Como hemos señalado, la tensión entre un modo de caracterización esteticista y una lectura más atenta a la dimensión política de la producción literaria latinoamericana de fines del siglo XIX y principios del XX atraviesa las diferentes formas de síntesis crítica del modernismo. En una dirección, para resolverla en el predominio de un registro sobre el otro. En otro itinerario, para asegurar su condición estructural. En esta última línea hemos destacado diversas formas de problematización de aquella tensión; desde una crítica que hace foco en el lugar de enunciación del discurso literario y que, por lo mismo, da cuenta de los límites políticos de la identificación inmediatamente emanciapatoria del ejercicio de la autonomía del campo cultural; hasta la perspectiva que destaca las contradicciones relativamente estructurales entre las pretensiones emancipatorias del modernismo y los dispositivos disciplinarios sobre los cuales se comprende. 


\section{Referencias bibliográficas}

Aguilar, Gonzalo (2010). "David Viñas, la crítica literaria y el cierre del pasado histórico", en Prismas, N 14.

Arellano, Jorge Eduardo (1993). Azul...de Rubén Dario. Nuevas perspectivas. Washington D. C.: Organización de los Estados Americanos.

Barbará de Bittar, E. (1970). "Introducción I", en Zuleta, Emilia (dir.), Bibliografia anotada del modernismo. Mendoza: Universidad Nacional de Cuyo.

Blanco Fombona, Rufino (1929). El modernismo y los poetas modernistas. Madrid: Mundo Latino.

Callinescu, Matei (1991). Cinco caras de la modernidad. Madrid: Tecnos.

Castro Gómez, Santiago (1996). Crítica de la razón latinoamericana. Barcelona: Puvill.

Castro Gómez, Santiago (1997). "Los vecindarios de la ciudad letrada. Variaciones filosóficas sobre un tema de Ángel Rama”, en Moraña, Mabel (ed.), Ángel Rama y los estudios latinoamericanos. Pisttsburgh: Universidad de Pittsburg.

Davison, Ned (1971). El concepto de modernismo en la crítica hispánica. Buenos Aires: Nova.

Díaz Plaja, Guillermo (1951). Modernismo frente a Noventa y ocho. Madrid: Espasa-Calpe.

Ferreres, Rafael (1964). Los límites del modernismo y del 98. Madrid: Taurus.

Franco, Jean (1971). La cultura moderna en América Latina. México: Joaquín Mortiz.

Gálvez, Manuel (1961). Amigos y maestros de mi juventud (Recuerdos de la vida literaria). Buenos Aires: Hachette.

Gomes, Miguel (2002). Estética del modernismo hispanoamericano. Caracas: Biblioteca Ayacucho.

Gullón, Ricardo (1963). Direcciones del modernismo. Madrid: Gredos.

Gutiérrez Girardot, Rafael (1983). Modernismo. Barcelona: Montesinos.

Gutiérrez Girardot, Rafael (1987). "La literatura hispanoamericana de fin de siglo". En: Iñigo Madrigal, Luis, Historia de la literatura hispanoamericana, Tomo II, Madrid: Cátedra. 
Henríquez Ureña, Max (1962). Breve historia del modernismo. México: Fondo de Cultura Económica.

Henríquez Ureña, Pedro (1980). Obras completas. Tomo X. Santo Domingo: Universidad Nacional Pedro Henríquez Ureña.

Jiménez; Juan Ramón (1962). El modernismo, notas de un curso. Madrid: Aguilar.

Jitrik, Noé. (1978) Las contradicciones del modernismo. México: El Colegio de México.

Jitrik, Noé. (1987) "El sistema modernista (o rubendariano)". En: Schulman, Iván (ed.), Nuevos asedios al modernismo. Madrid: Taurus.

Kant, Emmanuel (1992). Crítica de la facultad de juzgar. Caracas: Monte Ávila.

Kirpatrick, Gwen (2005). Disonancias del modernismo. Buenos Aires: Libros del Rojas.

Lee, Sohyun (2004). "El modernismo hispanoamericano: una nueva civilización para una nueva raza". En: Divergencias. Revista de Estudios Lingüisticos y literarios, Volumen 2, $\mathrm{N}^{\circ} 2$.

Litvak, Lily (1986). El modernismo. Madrid: Taurus.

Machado, Manuel (1913). La guerra literaria (1898-1914). Madrid: Imprenta Hispano-Alemana.

Maíz, Claudio (2007). "El modernismo hispanoamericano. Expresiones diversas de un rechazo. En: Cuadernos de Cátedra Miguel de Unamuno, 44.

Mapes, Erwin K. (1925). L'influence française dans l'œuvre de Rubén Darío. París: Librarie Anciene Honore Champion.

Marinello, Juan (1958). José Martí, escritor americano: Martí y el modernismo. México: Grijalbo.

Marinello, Juan (1959). Sobre el modernismo: polémica y definición. México: Universidad Nacional Autónoma de México.

Monguió, Luis (1974). "Sobre la caracterización del modernismo". En: Castillo, Homero, Estudios críticos sobre el modernismo. Madrid: Gredos.

Montaldo, Graciela (1994). La sensibilidad amenazada. Fin de siglo y modernismo. Rosario: Beatriz Viterbo. 
Pérez, Alberto Julian (1995). Modernismo, vanguardia, postmodernidad. Ensayos de literatura hispanoamericana. Buenos Aires: Corregidor.

Onís, Federico de (1974). "Sobre el concepto de modernismo". En: Castillo, Homero, Estudios críticos sobre el modernismo. Madrid: Gredos.

Osorio, Nelson (2000). Las letras hispanoamericanas de fines del siglo XIX. Murcia: Universidad de Santiago de Chile - Universidad de Alicante.

Rama, Ángel (1983). Literatura y clase social. México: Folios.

Rama, Ángel (1985a). La ciudad letrada. New Hampshire: Ediciones del Norte.

Rama, Ángel (1985b). Rubén Dario y el modernismo. Caracas: Alfadil.

Rama, Ángel (1985c). Las máscaras democráticas del modernismo. Montevideo: Fundación Ángel Rama.

Rama, Ángel (1995a). "La democratización enmascaradora del tiempo modernista". En: Rama, Ángel, La crítica de la cultura en América Latina. Caracas: Biblioteca Ayacucho, selección y prólogos de Saul Sosnowski y Tomás Eloy Martínez.

Rama, Ángel (1995b). "La modernización literaria latinoamericana (18701910)”. En: Rama, Ángel, La crítica de la cultura en América Latina, Caracas: Biblioteca Ayacucho, selección y prólogos de Saul Sosnowski y Tomás Eloy Martínez.

Ramos, Julio (1989). Desencuentros de la modernidad en América Latina. Literatura y politica en el siglo XIX. México: Fondo de Cultura Económica.

Real de Azúa, Carlos (1986). "Modernismo e ideologías”. En: Punto de Vista, Año X, No 28.

Rodó, José Enrique (1956). Obras completas. Buenos Aires: Antonio Zamora.

Salinas, Pedro (1949). "El problema del modernismo en España, o un conflicto entre dos espíritus". En: Salinas, Pedro, Literatura española. Siglo XX. Mexico: Robredo.

Schulman, Iván (1969). Martí, Dario y el modernismo, Madrid: Gredos.

Schulman, Iván (comp.) (1987). Nuevos asedios al modernismo. Madrid: Taurus.

Ugarte, Manuel (1908). Las nuevas tendencias literarias. Valencia: Sempere. 
Valera, Juan (1915). Obras completas. T. XLI. Madrid: Imprenta Librería Alemana.

Viñas, David (1996). Literatura argentina y realidad política. De Lugones a Walsh. Buenos Aires: Sudamericana.

Yurkievich, Saúl (1976). Celebración del modernismo. Barcelona: Tusquets.

Yurkievich, Saúl (1987). "El sujeto transversal o la subjetividad caleidoscópica”. En: Schulman, Iván (ed.), Nuevos Asedios al modernismo. Madrid: Taurus.

Yurrkievich, Saúl (1996). La movediza modernidad. Madrid: Taurus.

Zabala, Iris M. (1992). Colonialism and Culture. Hispanic Modernisms and the Social Imaginary. Indianapolis: Indiana University Press.

Zum Felde, Alberto (1921). Crítica de la literatura uruguaya. Montevideo: Maximino García.

Zum Felde, Alberto (1930). Proceso intelectual del Uruguay y crítica de su literatura. Montevideo: Imprenta Nacional Colorada. 